\title{
Molecular docking studies of Chenopodium album Linn with Lanosterol synthase enzyme
}

\author{
Jupudi Vasantha Madhuri* \\ Geethanjali College of Engineering and Technology, Cheeryal, Hyderabad- 501301 \\ (Telangana ), India \\ LNS Prakash Goteti \\ Tech Mahindra Limited, Hyderabad- 500043 Telangana ), India \\ *Corresponding author. Email: jvmadhuri.fe@gcet.edu.in
}

\section{Article Info}

https://doi.org/10.31018/

jans.v13i2.2618

Received: March 13, 2021

Revised: May 10, 2021

Accepted: May 15, 2021

\section{How to Cite}

Madhuri, J.V. and Goteti, L. P. (2021). Molecular docking studies of Chenopodium album Linn with Lanosterol synthase enzyme.. Journal of Applied and Natural Science, 13(2), 491 - 495. https://doi.org/10.31018/jans.v13i2.2618

\begin{abstract}
Cardiovascular diseases (CVD) are the major cause of death among people across the globe. Hypercholesterolemia is one of the major contributing factors for CVD. Molecules that bind with Lanosterol synthase enzyme, can be potential drug targets. Statin group of compounds like Simvastatin, cerivastatin, Atorvastatin etc., used for treating hypercholesterolemia have side effects and hence there is a growing demand for plant derived flavonoids. This work focusses on studying the compounds

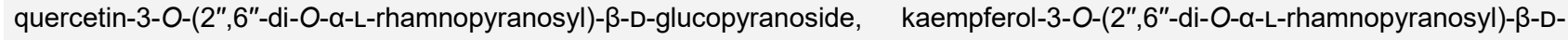
glucopyranoside, rutin; quercetin-3-O- $\beta$-D-glucopyranoside (Iso quercetin); and kaempferol-3-O- $\beta$-D-glucopyranoside (Astragalin) present in Chenopodium album Linn to inhibit Lanosterol synthase. Bioactivity score, drug likeness character was assessed in silico. Based on bioactivity spectrum, it is observed that the molecules are biologically active and the probability of these compounds to be biologically active is ranging from 0.784 to 0.992 , suggesting that these compounds are effective for treating hypercholesterolemia. In the molecular docking studies, the compounds binding affinity score was in agreement that the molecules have the potential to be used as an alternative to the statin group of compounds in treating cholesterol.
\end{abstract}

Keywords: Bioactivity, Chenopodium album, Hypercholesterolemia, Lanosterol synthase enzyme, Molecular docking

\section{INTRODUCTION}

Ethnomedicinal plants remain largely unexplored and there is a good scope for researchers and food processors to bring out these economical, easily grown plants to the mainstream food basket (Pala et al., 2019., Salmerón-ManzanoEsther et al., 2020). Chenopodium album Linn, is one such plant with good nutritive value (fibre, fatty acids and minerals). In India, it is called as Bathua and it belongs to Amaranthaceae family and Chenopodium genus (Bajwa Ali et al., 2019). C. Album is rich in flavonoids that play an important role in its pharmacological and therapeutic properties.

Flavonoids are phenolic compounds possessing a wide spectrum of biological activities and are studied for anticancer and reducing the risk of cardiovascular diseases caused by oxidative stress (AlexanderVictor et al., 2016, Thilakavathy Thangasamy et al., 2009). C.Album has been found to possess the bioflavonoids, Quercetin and Kaempferol derivatives (Gohar and Elmazar 1997,
Cutillo et al., 2006, Laghari et al.,2011) Hypercholesterolemia is considered as one of the factors for coronary heart diseases. Chemically synthesised drugs used to treat hypercholesterolemia contain statin group that on prolonged use causes muscle weakness, memory loss and inhibits coenzyme Q10 important for electron transfer in mitochondria (Wagstaff et al., 2003, Jamolowicz Al et al., 2015). In this context, it is highly relevant to focus on plant derived flavonoids that are effective in treating hypercholesterolemia.

Lanosterol synthase, also known as lanosterol cyclase, is a microsomal enzyme and a target for drugs lowering cholesterol (Telford et al., 2005, Vanessa et al., 2018). The potential anti-cholesteremic drug binds to the active sites of the Lanosterol synthase enzyme and inhibits it. To establish a plant derived flavonoid as a potential bioactive compound, it is important that we screen it theoretically and know its pharmacological and binding properties.

In the present work, we carried out in-silico calculation 
of bioactivity scores and drug like nature of the selected compounds from C.album through Molinspiration (www.molinspiration.com ) (Khan et al., 2017). In this calculation, it is observed that the selected molecules did not obey the Lipinski's rule of 5 (Lipinski., 2004). However, biological activity spectrum of the compounds using PASS tool (Prediction of Activity Spectra for Substances) exhibits anti-cholesteremic activity. Structure based docking approach is used to search for new drug targets assisting the process of new drug discovery. To evaluate the binding of these compounds with Lanosterol synthase enzyme, a grid-based docking method, Dockthor is used (Santos et al., 2020). The present study aimed to calculate bioactivity spectrum of selected flavonoids present in C. album and their binding affinity towards Lanosterol synthase enzyme to act as a potential candidate for lowering cholesterol.

\section{MATERIALS AND METHODS}

\section{Experimental}

Flavonoids identified in C.album chosen for the present study were, quercetin-3-O-(2",6"-di-O- $\alpha-$-Lrhamnopyranosyl)- $\beta$-D-glucopyranoside

11498684), kaempferol-3-O-(2",6"-di-O- $\alpha-L-$ rhamnopyranosyl)- $\beta$-D-glucopyranoside (CID 10485148), rutin (CID5280805); quercetin-3-O- $\beta-D-$ glucopyranoside (Iso quercetin) (CID 5280804); and kaempferol-3-O- $\beta$-D-glucopyranoside (Astragalin) (CID 5282102) were obtained from pubchem. Similarly, Lanosterol synthase (1W6J) was taken from Protein Data Bank (PDB) and these structures were used for insilico analysis.

In Molinspiration, the bioactivity score of a molecule were calculated by its interaction with GPCR ligand, ion channel modulator, nuclear receptor ligand, kinase, protease and enzyme inhibitors then comparing it with a standard drug. If the bioactivity score is greater than zero, then it is active, moderately active if the bioactivity score lies between -5.0 and 0.0 and inactive if less than 5.0. Drug likeness of the compounds was calculated using Lipinski's rule of 5 (Lipinski., 2004).

The key feature of PASS tool is to predict the biological activity spectrum of the compounds based on its chemi- cal structure. Biological activity of a compound is considered as an intrinsic property and in PASS it is described by descriptors called Multilevel Neighborhoods of Atoms (MNA) (Filimonov et al., 1999). Structural information of the molecule was processed as MNA descriptors that are generated in the program and based on the training set, $\mathrm{Pa}$ (probability of the compound to be active) and $\mathrm{Pi}$ (probability of the compound to be inactive) were generated for each biological activity. The values of $\mathrm{Pa}$ and $\mathrm{Pi}$ varied between 0.000 to 1.000 and $\mathrm{Pa}+\mathrm{Pi}<1$. Though the compounds with $\mathrm{Pa}>0.8$ were promising, they can match to an already existing chemical entity. So, there is a probability of finding New Chemical Entities (NCE) for the compounds with the activity range, $0.5<\mathrm{Pa}<0.7$ (Khan et al., 2017). However, in the present work, we were looking for the potential anti-cholesteremic activity of the compounds.

Dockthor program is developed by GMMSB/LNCC group and it uses MMFF94S force field as scoring function (Guedes et al., 2021). It can easily dock highly flexible compounds with up to 40 rotatable bonds (Santos et al., 2020). The grid center was chosen as 40 and grid center was assigned for each ligand. Binding affinity, total energy was calculated to predict the compound's affinity in binding with lanosterol synthase.

\section{RESULTS AND DISCUSSION}

In the recent past, there is a growing demand for naturally occurring antioxidants that play a role in inhibiting reactive oxygen species within the tissues and free radicals (Garnatje et al., 2017, Guarise et al., 2019). Polyphenols are such compounds that are present in plants exhibiting some important pharmacological properties. Polyphenols exhibit antioxidant property by scavenging free radicals, chelate with metal ions, inhibit oxidases, terminate free radical reactions (Vanessa et al., 2018). C. Album is rich in polyphenols (Table 1) and has potential to serve as natural antioxidants.

Pharmacological activity of a compound depends on the binding affinity towards the biological or drug target. The most common targets are enzymes, ion channel modulators, receptors etc. In this study, the bioactivity

Table 1. Bioactivity score of selected compounds of $C$. album.

\begin{tabular}{llllllll}
\hline & & \multicolumn{7}{c}{ Bioactivity score parameters } \\
\cline { 3 - 8 } S. No & Compound & $\begin{array}{l}\text { GPCR } \\
\text { ligand }\end{array}$ & $\begin{array}{l}\text { lon channel } \\
\text { modulator }\end{array}$ & $\begin{array}{l}\text { Kinase } \\
\text { inhibitor }\end{array}$ & $\begin{array}{l}\text { Nuclear receptor } \\
\text { ligand }\end{array}$ & $\begin{array}{l}\text { Protease } \\
\text { inhibitor }\end{array}$ & $\begin{array}{l}\text { Enzyme } \\
\text { inhibitor }\end{array}$ \\
\hline 1 & CID 11498684 & -1.02 & -2.09 & -1.53 & -1.68 & -0.72 & -1.15 \\
2 & CID 10485148 & -0.88 & -1.89 & -1.35 & -1.42 & -0.59 & -0.99 \\
3 & CID 5280805 & -0.05 & -0.52 & -0.14 & -0.23 & -0.07 & 0.12 \\
4 & CID 5280804 & 0.05 & -0.04 & 0.13 & 0.19 & -0.05 & 0.41 \\
5 & CID 5282102 & -0.05 & 0.10 & 0.10 & 0.20 & -0.05 & 0.41 \\
\hline
\end{tabular}


score was calculated by binding to $G$ protein-coupled receptor (GPCR), ion channel modulator, nuclear receptor and kinase, protease, enzyme inhibitors. From table 1 , it was observed that the values were in the range 0.0 and -5.0 suggesting moderate bioactivity for the selected compounds of the C.album. This indicated that the selected compounds possessed properties that may be explored for potential drug activity.

Lipinski's rule of 5 , screens out the molecules based on molecular weight, partition coefficient (log P), TPSA (Topological polar surface area), number of rotatable bond and number of hydrogen bond donors and acceptors. Small molecules generally may be screened using this rule, but with increasing demand for plant derived drug molecules that are generally large, it is difficult to comply with the rule but can still be biologically active. It is observed that, there are many FDA approved biological molecules that do not obey Lipinski's rule of 5 (Zhang MQ et al., 2007). Table 2 depicts the scores of the compounds for Lipinski's rule of 5 . From the table, it may be observed that, only two compounds, CID 5280804 and CID 5282102 had molecular weight less than 500 and also number of rotatable bonds less than 5 . It may be observed that, the partition coefficient value is less than 5 for all the compounds, suggesting good membrane permeability. But the number of Hydrogen bond acceptors and donors are not in the range of Lipinski's rule of 5 .

These compounds can be biological antioxidants that can scavenge free radicals and decrease the oxidative stress damage caused to the body and hence they can be used as dietary antioxidants. Further continuing the study, the biological activity spectrum of the compounds was studied using 'PASS' to know whether the compounds have the potential to be pharmacologically active or not. Biological activities like free radical scavenging, antioxidants, lipid peroxidase and kinase inhibitors influence hypercholesterolemia (CharlesSchoeman et al., 2015, Lee et al.,2014). Hence, from the biological spectrum of the compounds, the $\mathrm{Pa}$ and

Table 2. Lipinski rule of 5 for selected compounds of $C$. album.

\begin{tabular}{llllllll}
\hline $\begin{array}{l}\text { S. } \\
\text { No }\end{array}$ & Compound & $\begin{array}{l}\text { Mol weight } \\
\text { g/mol }\end{array}$ & LogP & $\begin{array}{l}\text { TPSA }\left(\AA^{2}\right) \text { Topological } \\
\text { polar surface area }\end{array}$ & $\begin{array}{l}\text { H-bond } \\
\text { acceptor }\end{array}$ & $\begin{array}{l}\text { H-bond } \\
\text { donor }\end{array}$ & $\begin{array}{l}\text { Number of } \\
\text { rotatable bonds }\end{array}$ \\
\hline 1. & CID 11498684 & 756.7 & -1.76 & 328.35 & 20 & 12 & 8 \\
2. & CID 10485148 & 740.7 & -1.35 & 308.12 & 19 & 11 & 8 \\
3. & CID5280805 & 610.5 & -1.06 & 269.43 & 16 & 10 & 6 \\
4. & CID 5280804 & 463.4 & -2.96 & 213.33 & 12 & 7 & 4 \\
5. & CID 5282102 & 448.4 & 0.12 & 190.28 & 11 & 7 & 4 \\
\hline
\end{tabular}

Table 3. Pa and Pi values from the biological spectrum of $C$. album.

\begin{tabular}{lllllllll}
\hline \multirow{2}{*}{ Compound } & \multicolumn{9}{c}{ Biological activity } \\
\cline { 2 - 9 } & $\begin{array}{l}\text { Free radical } \\
\text { scavenger }\end{array}$ & \multicolumn{3}{c}{$\begin{array}{l}\text { Lipid peroxidase } \\
\text { inhibitor }\end{array}$} & \multicolumn{2}{c}{ Antioxidant } & \multicolumn{2}{c}{ Kinase inhibitor } \\
\cline { 2 - 10 } & $\mathbf{P a}$ & $\mathbf{P i}$ & $\mathbf{P a}$ & $\mathbf{P i}$ & $\mathbf{P a}$ & $\mathbf{P i}$ & $\mathbf{P a}$ & $\mathbf{P i}$ \\
\hline CID 11498684 & 0.992 & 0.001 & 0.989 & 0.001 & 0.934 & 0.002 & 0.801 & 0.006 \\
CID 10485148 & 0.982 & 0.001 & 0.966 & 0.002 & 0.897 & 0.003 & 0.784 & 0.007 \\
CID 5280805 & 0.988 & 0.001 & 0.987 & 0.001 & 0.923 & 0.003 & 0.819 & 0.005 \\
CID 5280804 & 0.978 & 0.001 & 0.980 & 0.001 & 0.910 & 0.003 & 0.804 & 0.005 \\
CID 5282102 & 0.969 & 0.001 & 0.960 & 0.002 & 0.907 & 0.003 & 0.837 & 0.004 \\
\hline
\end{tabular}
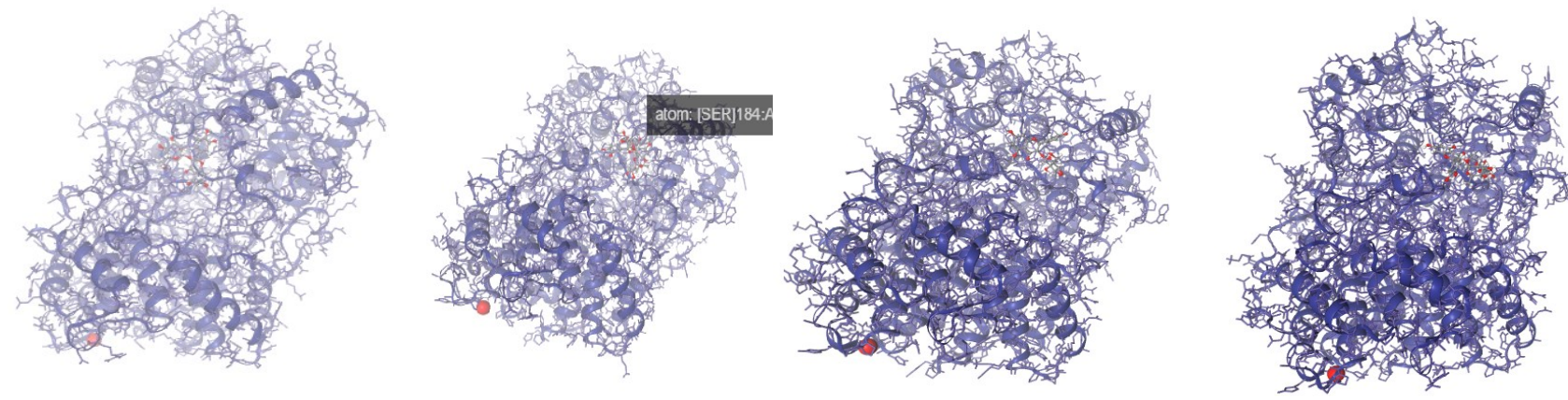

Fig. 1. Molecular docking of the compounds with Lanosterol synthase. 
Madhuri, J.V. and Goteti, L. P. / J. Appl. \& Nat. Sci. 13(2), 491 - 495 (2021)

Table: 4. Binding affinity and docking parameters compounds present in C.Album with Lanosterol Synthase.

\begin{tabular}{llll}
\hline Compound & Binding affinity kcal/mol & $\begin{array}{l}\text { Total Energy } \\
\text { kcal/mol }\end{array}$ & $\begin{array}{l}\text { Vander Waals energy } \\
\mathbf{k c a l} / \mathbf{m o l}\end{array}$ \\
\hline CID 11498684 & -7.743 & 69.277 & -15.760 \\
CID 10485148 & -7.311 & 50.143 & -11.971 \\
CID 5280805 & -7.860 & 50.468 & -17.356 \\
CID 5280804 & -7.692 & 69.064 & -14.482 \\
CID 5282102 & -7.743 & 69.277 & -15.760 \\
\hline
\end{tabular}

$\mathrm{Pi}$ values of the mentioned biological activities are listed for the compounds present in C.album in Table3. Activity of the compound is predicted based on the Bayesian approach, where the structure of the compound is compared with that of the existing active substrate in the database. Leave-one-out cross-validation (LOO CV) estimates the accuracy of the method to be 95\% (Filimonov et al., 1999). From the table, it is clear that the probability of the compounds to be biologically active for the particular activity was ranging from 0.784 to 0.992 , suggesting that these compounds are effective for treating hypercholesterolemia.

Molecular docking studies with lanosterol synthase and the compounds of C.album using dockthor gave information about the binding affinity, most stable structure and binding mode. According to the present docking studies, the binding affinity for all the molecules is in the same range, but for kaempferol-3-O-(2",6"-di-O- $\alpha-\mathrm{L}$ -rhamnopyranosyl)- $\beta$-D-glucopyranoside, the other parameters like total energy, Vander Waals energy is also promising, as seen in Table 4. The present study observed that all the ligands bind with lanosterol synthase, as shown in Fig.1. This clearly indicates that these compounds have the potential to serve as dietary antioxidants. The present study observed that all the ligands bind with lanosterol synthase. Further studies may be taken up to establish these plant - derived compounds as an alternative to statin group in treating hypercholesterolemia.

\section{Conclusion}

The present study observed that compounds in C.album have the potential to be used as an alternative to the statin group of compounds in treating cholesterol. Even though, the compounds do not obey Lipinski's rule of 5 , they have potential biological activity as observed in the biological spectrum of the compound. This is also evident from $\mathrm{Pa}, \mathrm{Pi}$ values and as well as docking studies. C.album has a nutritive and therapeutic value that may be exploited to impart nutrition and prepare functional foods. With many biologically active constituents present in it, they may be isolated and further studies may be taken up for the development of drugs. With increasing societal awareness towards health and with emerging new technologies like synthetic biology, there will be demand for plant derived drug molecules and their derivatives in treating, especially lifestyle disorders.

\section{Conflict of interest}

The authors declare that they have no conflict of interest.

\section{REFERENCES}

1. Alexander Victor, Anand David, Radhakrishnan A. \& Subramani, P. (2016). Overviews of Biological Importance of Quercetin: A Bioactive Flavonoid, Pharmacognosy reviews., 10(20), 84-89. doi:10.4103/09737847.194044.

2. Bajwa $A A$, Zulfiqar $U$, Sadia $S$, Bhowmik $P$ \& Chauhan BS. (2019). A global perspective on the biology, impact and management of Chenopodium album and Chenopodium murale: two troublesome agricultural and environmental weeds. Environmental Science and Pollution Res earch, 26, 5357 - 5371 https://doi.org/10.1007/s11356-01 8-04104-y.

3. Cutillo F, DellaGreca M, Gionti M, Previtera L \& Zarrelli A. (2006). Phenols and lignans from Chenopodium album. Phytochem Anal. 17(5), 344-349. doi:10.1002/pca.924.

4. Charles-Schoeman C, Fleischmann R, Davignon J, Schwartz H, Turner SM, Beysen C, Milad M, Hellerstein MK, Luo Z, Kaplan IV, Riese R, Zuckerman A \& Mclnnes IB. (2015). Potential mechanisms leading to the abnormal lipid profile in patients with rheumatoid arthritis versus healthy volunteers and reversal by tofacitinib. Arthritis Rheumatol., 67(3), 616-625. doi: 10.1002/art.38974.

5. FilimonovD, PoroikovV \& Borodina GloriozovaT. (1999). Chemical Similarity Assessment Through Multilevel Neighborhoods of Atoms: Definition and Comparison with the Other Descriptors. J. Chem. Inf. Comput. Sci. 39(8), 666670.

6. GoharAA \& Elmazar MMA (1997). Isolation of hypotensive flavonoids from Chenopodium species growing in Egypt. Phytother Res., 11, 564-567.

7. Guedes, I. A, Barret A. M. S, Marinho, Krempser E, Kuenemann MA, Sperandio O, Dardenne L E \& Miteva M A. (2021). Machine Learning and Physics-Based Scoring Functions for Drug Discovery. Sci.Rep., 11 (1), 31983217. https://doi.org/10.1038/s41598-021-82410-1.

8. GarnatjeT, Peñuelas J \& Vallès, (2017) Ethnobotany, phylogeny, and 'omics' for human health and food security. 
Madhuri, J.V. and Goteti, L. P. / J. Appl. \& Nat. Sci. 13(2), 491 - 495 (2021)

Trends Plant Sci., 22(3), 187-191. DOI: 10.1016/ j.tplants.2017.01.001

9. Guarise M, Borgonovo G, Bassoli A \& Ferrante A. (2019). Evaluation of two wild populations of Hedge Mustard (Sisymbrium officinale (L.) Scop.) as a potential leafy vegetable. Horticulturae., 5(1), 13-23, https://doi.org/10.3390/ horticulturae5010013

10. Jamolowicz Al, Chen HY \& Panegyres PK (2015). Statins and memory loss: An Australian experience. Australas Med J., 8(3), 73-79. doi: 10.4066/AMJ.2015.2014.

11. Khan T, Dixit S, Ahmad R, Raza S, Azad I, Joshi S \& Khan AR. (2017). Molecular docking, PASS analysis, bioactivity score prediction, synthesis, characterization and biological activity evaluation of a functionalized 2butanone thiosemicarbazone ligand and its complexes. J.Chem.Biol., 10(3), 91-104. https://doi.org/10.1007/ s12154-017-0167-y.

12. Laghari $\mathrm{AH}$, Memon $\mathrm{S}$, Nelofar $\mathrm{A}$, Khan KM \& Yasmin $\mathrm{A}$. (2011). Determination of free phenolic acids and antioxidant activity of methanolic extracts obtained from fruits and leaves of Chenopodiumalbum. Food Chem., 126(4), 1850-1855. doi: 10.1016/j.foodchem.2010.11.165.

13. Lipinski, Christopher. (2004). Lead- and drug-like compounds: the rule-of-five revolution. Drug Discov. Today Technol., 1(4), 337-341. DOI:10.1016/j.ddtec.2004.11.007

14. Lee JC, Park BK, Choung S, Kim JM, Joung KH, Lee JH, Kim KS, Kim HJ, Jeong JW, Rhee SD \& Ku BJ. (2014). Amelioration of Hypercholesterolemia by an EGFR Tyrosine Kinase Inhibitor in Mice with Liver-Specific Knockout of Mig-6. PLOS ONE 9(12): 1-13. https://doi.org/10.1371/ journal.pone.0114782

15. Morand OH, Aebi JD, Dehmlow H, Ji YH, Gains N, Lengsfeld H \& Himber J. (1997). Ro 48-8071, a new 2,3oxidosqualene: lanosterol cyclase inhibitor lowering plasma cholesterol in hamsters, squirrel monkeys, and minipigs: comparison to simvastatin. Journals of Lipid Research., 38(3), 373-390.

16. Pala, N.A., Sarkar B.C., Shukla, G, Nakul C Shovik D., Jahangeer $A B$ \& Sumit $C$ (2019). Floristic composition and utilization of ethnomedicinal plant species in home gardens of the Eastern Himalaya. J Ethnobiology Ethnomedicine., 15(14), 1-16. https://doi.org/10.1186/s13002019-0293-4
17. Santos KB, Guedes IA, Karl ALM \& Dardenne LE. (2020). Highly Flexible Ligand Docking: Benchmarking of the DockThor Program on the LEADS-PEP Protein-Peptide Data Set, J.Chem.Inf Model., 60 (2), 667-683. doi: 10.1021/acs.jcim. 9b00905.

18. Salmerón-ManzanoEsther, Garrido-Cardenas Jose A \& Manzano-Agugliaro, Francisco (2020). Worldwide Research Trends on Medicinal Plants. Int. J. Environ. Res. Public Health 17(10) 3376-3396. https://doi.org/10.3390/ ijerph17103376

19. Telford DE, Lipson SM, Barrett PH, Sutherland BG, Edwards JY, Aebi JD, Dehmlow H, Morand OH \& Huff MW. (2005). A Novel Inhibitor of Oxidosqualene:Lanosterol Cyclase Inhibits Very LowDensity Lipoprotein Apolipoprotein B100 (ApoB100) Production and Enhances Low-Density Lipoprotein ApoB100 Catabolism Through Marked Reduction in Hepatic Cholesterol Content. Arteriosclerosis, Thrombosis, and Vascular Biology., 25(12), 26082614. https://doi.org/10.1161/01.ATV.0000189158.2845 5. 94

20. Thilakavathy Thangasamy, Sivanandane Sittadjody \& Randy Burd (2009). Chapter 27 - Quercetin: A Potential Complementary and Alternative Cancer Therapy, Complementary and Alternative Therapies and the Aging Population, Academic Press., 563-584. https:// doi.org/10.1016/B978-0-12-374228-5.00027-5.

21. Vanessa Sales de Oliveira, Fernanda Silva Ferreira, Maria Clara Ramos Cople, Tatiana da Silva Labre, Ivanilda Maria Augusta, Ormindo Domingues Gamallo \&Tatiana Saldanha (2018), Use of Natural Antioxidants in the Inhibition of Cholesterol Oxidation: A Review. Comprehensive Reviews in Food Science and Food Safety., 17(2), 1465-1483. https://doi.org/10.1111/1541 $-4337.12386$

22. Wagstaff LR, Mitton MW, Arvik BM \& Doraiswamy PM., (2003). Statin-associated memory loss: analysis of 60 case reports and review of the literature. Pharmacotherapy., 23(7), 871-880. doi: 10.1592/phco.2 3.7.871.32720.

23. Zhang $M Q \&$ Barrie Wilkinson, (2007) Drug discovery beyond the 'rule-of-five'. Curr.Opin.Biotechnol., 18(6), 478-488. https://doi.org/10.1016/j.copbio.2007.10.005. 